\title{
Endoscopic third ventriculostomy and repeat endoscopic third ventriculostomy in pediatric patients: the Dutch experience
}

\author{
Gerben E. Breimer, MD, PhD, ${ }^{1,2}$ Ruben Dammers, MD, PhD, ${ }^{3}$ Peter A. Woerdeman, MD, PhD, ${ }^{4}$ \\ Dennis R. Buis, MD, PhD, ${ }^{5,6}$ Hans Delye, MD, PhD, ${ }^{7}$ Marjolein Brusse-Keizer, $\mathrm{PhD},{ }^{8}$ and \\ Eelco W. Hoving, MD, PhD, ${ }^{1}$ on behalf of the Dutch Pediatric Neurosurgery Study Group
}

\begin{abstract}
${ }^{1}$ Department of Neurosurgery, University Medical Center Groningen; Departments of ${ }^{2}$ Pathology and ${ }^{5}$ Neurosurgery, Academic Medical Center Amsterdam; ${ }^{3}$ Department of Neurosurgery, Erasmus MC, Sophia Children's Hospital, Rotterdam; ${ }^{4}$ Department of Neurosurgery, Rudolf Magnus Institute of Neuroscience, University Medical Center, Utrecht; ${ }^{6}$ Department of Neurosurgery, VU University Medical Center, Neurosurgical Center Amsterdam; ${ }^{7}$ Department of Neurosurgery, Radboud University Nijmegen Medical Centre, Nijmegen; and ${ }^{8}$ Medical School Twente, Medisch Spectrum Twente Hospital, Enschede, The Netherlands
\end{abstract}

OBJECTIVE After endoscopic third ventriculostomy (ETV), some patients develop recurrent symptoms of hydrocephalus. The optimal treatment for these patients is not clear: repeat ETV (re-ETV) or CSF shunting. The goals of the study were to assess the effectiveness of re-ETV relative to initial ETV in pediatric patients and validate the ETV success score (ETVSS) for re-ETV.

METHODS Retrospective data of 624 ETV and 93 re-ETV procedures were collected from 6 neurosurgical centers in the Netherlands (1998-2015). Multivariable Cox proportional hazards modeling was used to provide an adjusted estimate of the hazard ratio for re-ETV failure relative to ETV failure. The correlation coefficient between ETVSS and the chance of re-ETV success was calculated using Kendall's tau coefficient. Model discrimination was quantified using the c-statistic. The effects of intraoperative findings and management on re-ETV success were also analyzed.

RESULTS The hazard ratio for re-ETV failure relative to ETV failure was 1.23 (95\% Cl 0.90-1.69; $p=0.20$ ). At 6 months, the success rates for both ETV and re-ETV were $68 \%$. ETVSS was significantly related to the chances of reETV success $(\tau=0.37 ; 95 \%$ bias corrected and accelerated $\mathrm{Cl} 0.21-0.52 ; \mathrm{p}<0.001)$. The c-statistic was $0.74(95 \% \mathrm{Cl}$ 0.64-0.85). The presence of prepontine arachnoid membranes and use of an external ventricular drain (EVD) were negatively associated with treatment success, with ORs of $4.0(95 \% \mathrm{Cl} 1.5-10.5)$ and $9.7(95 \% \mathrm{Cl} 3.4-27.8)$, respectively. CONCLUSIONS Re-ETV seems to be as safe and effective as initial ETV. ETVSS adequately predicts the chance of successful re-ETV. The presence of prepontine arachnoid membranes and the use of EVD negatively influence the chance of success.

https://thejns.org/doi/abs/10.3171/2017.4.PEDS16669

KEY WORDS pediatrics; hydrocephalus; neuroendoscopy; ventriculostomy; reoperation; ETVSS

$\mathrm{E}$ NDOSCOPIC third ventriculostomy (ETV) has become the standard treatment for obstructive hydrocephalus. ${ }^{29}$ Its range of indications has extended to communicative hydrocephalus as well. ${ }^{29,49}$ Unfortunately, to date, no treatment modality guarantees a permanent solution for hydrocephalus. ${ }^{32}$ Therefore, when primarily treating hydrocephalus, the apparent benefits and disad- vantages of ETV and shunting have to be weighted and considered. . $^{10,16,18,30,36,38,41,61}$ To facilitate neurosurgeons in the process of patient selection for ETV, a predictive model was developed that estimates the chance of ETV success over a 6-month period: the so-called ETV Success Score (ETVSS). $5,17,20,25,37,47$

When a patient is referred for suspicion of recurrent

ABBREVIATIONS ELD = external lumbar drain; ETV = endoscopic third ventriculostomy; ETVSS = ETV Success Score; EVD = external ventricular drain; IQR = interquartile range; $L P=$ lumbar puncture; re-ETV = repeat ETV.

SUBMITTED December 7, 2016. ACCEPTED April 11, 2017.

INCLUDE WHEN CITING Published online July 14, 2017; DOI: 10.3171/2017.4.PEDS16669. 
hydrocephalus, the neurosurgeon has 2 treatment options: either perform a repeat ETV (re-ETV) or implant a CSF shunt.

A Dutch external validation study of ETVSS found a $78 \%$ success rate for the group that underwent re-ETV after an evaluation period of 6 months. ${ }^{5}$ However, the sample size was relatively small, with 18 patients receiving re-ETV. This prompted us to design the current retrospective multicenter study in which data from 6 university neurosurgical centers in the Netherlands were clustered to investigate these findings using a larger sample size. In this paper, we report on the observed effectiveness of re-ETV relative to the observed effectiveness of initial ETV and determine the predictive accuracy of ETVSS in patients undergoing re-ETV. An additional aim is to provide an in-depth analysis of re-ETV patients and the factors that influence the chance of success.

\section{Methods}

\section{Study Design}

Retrospective data were gathered from the electronic patient records of 6 university medical centers in the Netherlands: Academic Medical Center, Amsterdam (July 1999 to February 2015), VU University Medical Center, Amsterdam (most data obtained between August 2010 and October 2014), University Medical Center, Groningen (April 1998 to November 2014), Radboud University Medical Center, Nijmegen (most between January 2004 and August 2014), Erasmus University Medical Center, Rotterdam (May 1997 to December 2014), and University Medical Center, Utrecht (most between April 2004 and July 2013). The cooperating centers are included in the Dutch Pediatric Neurosurgical Study Group.

The participating neurosurgical clinics are high-volume university hospitals with dedicated neurosurgeons who specialize in pediatric and/or endoscopic procedures. Therefore, the neurosurgeons involved in these procedures (performance or supervision and patient selection) should be considered experienced.

All ETV procedures were performed in accordance with national guidelines, i.e., either by a neurosurgeon or a resident under the direct supervision of a neurosurgeon. ETV failure was defined as any subsequent surgical procedure for CSF diversion, as determined by a neurosurgeon, or death related to hydrocephalus management. ${ }^{15}$

The research protocol was submitted to and approved by an ethics committee. Patient consent was not required as we worked with an anonymized retrospective data set and did not use an intervention.

\section{Data Collection}

All patients who were younger than 18 years at the time of ETV were eligible for inclusion. The following patient characteristics were collected: etiology (classified as aqueductal stenosis, postinfectious, myelomeningocele, post-intraventricular hemorrhage, tectal tumor, nontectal brain tumor, or other cause), date of birth, sex, date of initial ETV, date of ETV failure (defined as any subsequent surgical procedure for CSF diversion or hydrocephalusrelated death), date of re-ETV, date of re-ETV failure (us-

\section{ETV SUCCESS SCORE}

$=$ Age Score + Etiology Score + Previous Shunt Score
$\approx$ percentage probability of ETV success

\begin{tabular}{|c|c|c|c|}
\hline SCORE & \multicolumn{3}{|c|}{$\begin{array}{c}\text { AGE + ETIOLOGY + PREVIOUS } \\
\downarrow \\
\downarrow\end{array}$} \\
\hline 0 & < MONTH & POSTANFECTIOUS & PREVIOUS SHUNT \\
\hline 10 & $\begin{array}{c}1 \text { MONTH } \\
\text { TO<6 } \\
\text { MONTHS }\end{array}$ & & $\begin{array}{l}\text { NO } \\
\text { PREVIOUS SHUNT }\end{array}$ \\
\hline 20 & & $\begin{array}{l}\text { MYELOMENINGOCELE } \\
\text { INTR.VENTRICULAR } \\
\text { HEMORRHAGE } \\
\text { NON-TECTALBRAM } \\
\text { TUMOROR }\end{array}$ & \\
\hline 30 & $\begin{array}{l}6 \text { MONTHS } \\
\text { TO }<1 \text { YEAR }\end{array}$ & $\begin{array}{c}\text { AQUEDUCTAL } \\
\text { STENOSIS } \\
\text { TECALTUNOR } \\
\text { OTHER ETIOLOGY }\end{array}$ & \\
\hline 40 & $\begin{array}{c}1 \text { YEAR } \\
\text { TO<10 YEARS }\end{array}$ & & \\
\hline 50 & 210 YEARS & & \\
\hline
\end{tabular}

FIG. 1. Calculation of the ETVSS. Reprinted from Kulkarni et al: J Pediatr 155:254-259, 259.e1, 2009, with permission from Elsevier.

ing the previously mentioned definition), use of an external ventricular drain (EVD), lumbar puncture (LP), and/or external lumbar drain (ELD) postoperatively, shunt history, and last contact with the neurosurgery or neurology department for follow-up. Patient age was classified as used for the ETVSS score: younger than 1 month, 1 month to younger than 6 months, 6 months to younger than 1 year, 1 year to younger than 10 years, and equal to or older than 10 years.

The ETVSS for each patient's re-ETV was calculated using age, etiology, and previous shunt score (Fig. 1). ${ }^{37}$ For example, if a 9-month-old patient with hydrocephalus due to aqueductal stenosis who previously underwent CSF shunt placement is selected for an ETV, the chance of ETV success over a period of 6 months is $60 \%$ (30 for patient age +30 for etiology +0 for previous shunt $=60$ ).

The surgical reports were investigated for intraoperative findings at re-ETV, and these findings were reported in different categories: complete occluded stoma without underlying arachnoid membranes, complete occluded stoma with underlying arachnoid membranes, pinpoint stoma without underlying arachnoid membranes, pinpoint stoma with underlying arachnoid membranes, obstruction due to underlying prepontine arachnoid membranes alone, and no apparent occlusion.

\section{Statistical Analysis}

We reported categorical patient characteristics using the number and percentage observed, continuous normally distributed characteristics using the mean and SD, and continuous nonnormally distributed characteristics using 
TABLE 1. Demographics of the ETV and re-ETV patients

\begin{tabular}{lccc}
\hline & \multicolumn{3}{c}{ No. of Patients (\%) } \\
\cline { 2 - 4 } \multicolumn{1}{c}{ Characteristic } & $\begin{array}{c}\text { ETV } \\
(n=624)\end{array}$ & $\begin{array}{c}\text { Re-ETV } \\
(n=93)\end{array}$ & $\begin{array}{c}\text { Total } \\
(n=717)\end{array}$ \\
\hline Origin of hydrocephalus & & & \\
\hline Aqueductal stenosis & $123(19.7)$ & $19(20.4)$ & $142(19.8)$ \\
\hline Postinfectious & $18(2.9)$ & $3(3.2)$ & $21(2.9)$ \\
\hline Myelomeningocele & $40(6.4)$ & $5(5.4)$ & $45(6.3)$ \\
\hline Intraventricular hemorrhage & $44(7.1)$ & $6(6.5)$ & $50(7.0)$ \\
\hline Tectal tumor & $49(7.9)$ & $16(17.2)$ & $65(9.1)$ \\
\hline Other brain tumor (non-midbrain) & $195(31.3)$ & $16(17.2)$ & $211(29.4)$ \\
\hline Other & $155(24.8)$ & $28(30.1)$ & $183(25.5)$ \\
\hline Age at procedure & & & \\
\hline$<1$ mo & $44(7.1)$ & 0 & $44(6.1)$ \\
\hline $1-6$ mos & $110(17.6)$ & $15(16.1)$ & $125(17.4)$ \\
\hline 6 mos to <1 yr & $53(8.5)$ & $11(11.8)$ & $64(8.9)$ \\
\hline $1-10$ yrs & $227(36.4)$ & $34(36.6)$ & $261(36.4)$ \\
\hline$\geq 10$ yrs & $190(30.4)$ & $33(35.5)$ & $223(31.1)$ \\
\hline Shunt prior to procedure & & & \\
\hline Yes & $112(17.9)$ & $25(26.9)$ & $137(19.1)$ \\
\hline No & $512(82.1)$ & $68(73.1)$ & $580(80.9)$ \\
\hline
\end{tabular}

the median and interquartile range (IQR). We examined differences in the groups of patients using the chi-square test. Fisher's exact test was used to assess categorical variables, and the ORs were calculated with the 95\% CI. We used the independent 2-tailed t-test and Mann-Whitney U-test to assess continuous normally and nonnormally distributed variables, respectively.

Follow-up was calculated from the date the patient was first operated on to the date at which the patient was seen at the clinic and known to be well, and the date of subsequent treatment or date of death, whichever came first.

Survival curves were calculated using the Kaplan-Meier method. Survival analysis covering the time to ETV failure was performed using a Cox proportional hazards model. The proportional hazards assumption was checked visually with the Kaplan-Meier curves. Stratified ETVSS (low is $\leq 40$; moderate is $50-70$; high is $\geq 80$ ) and "ETV versus reETV" were entered into a multivariable Cox proportional hazards model because the literature supports the elements

\section{TABLE 2. Number of patients per institution}

\begin{tabular}{lcc}
\hline \multirow{2}{*}{\multicolumn{1}{c}{ Institution }} & \multicolumn{2}{c}{ No. of Patients (\%) } \\
\cline { 2 - 3 } & $\begin{array}{c}\text { ETV } \\
\text { Patients }\end{array}$ & $\begin{array}{c}\text { Re-ETV } \\
\text { Patients }\end{array}$ \\
\hline Erasmus University Medical Center, Rotterdam & $189(30.3)$ & $37(39.8)$ \\
\hline University Medical Center, Groningen & $202(32.4)$ & $36(38.7)$ \\
\hline Radboud University Medical Center, Nijmegen & $97(15.5)$ & $8(8.6)$ \\
\hline University Medical Center, Utrecht & $42(6.7)$ & $7(7.5)$ \\
\hline Academic Medical Center, Amsterdam & $62(9.9)$ & $3(3.2)$ \\
\hline VU Medical Center, Amsterdam & $32(5.1)$ & $2(2.2)$ \\
\hline
\end{tabular}

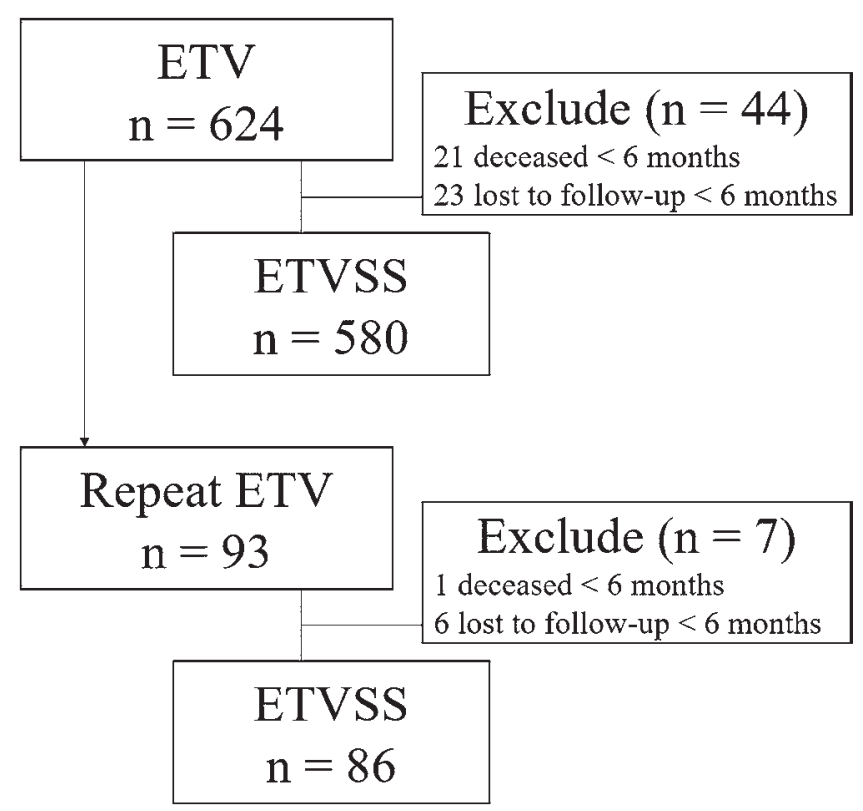

FIG. 2. Flowchart for selecting the patients with ETV and re-ETV enrolled in this study.

of the ETVSS as the most important confounders. ${ }^{37}$ This model was used to provide an adjusted estimate and 95\% $\mathrm{CI}$ of the HR for re-ETV failure relative to ETV failure.

Successful cases with less than 6 months of follow-up were excluded from testing of the predictive adequacy of the ETVSS, as this score predicts the chances of ETV success over a 6-month period. We determined the predictive adequacy of ETVSS by comparing the predicted probability of re-ETV success between patients with successful and failed re-ETV treatment using the independent t-test. Model discrimination was quantified by the area under the receiver operating characteristic curve (hereafter called the c-statistic) with $95 \% \mathrm{CI}$, and the correlation coefficient between ETVSS and chance of re-ETV success was calculated using Kendall's tau coefficient with the 95\% bootstrapped CI based on 1000 replications. We performed the same analysis for the initial ETV procedure on all patients who underwent surgery during the aforementioned dates at the cooperating centers.

We performed all data analyses using IBM SPSS Statistics for Windows (version 23.0; IBM Corp.) and considered $\mathrm{p}$ values less than 0.05 as statistically significant.

\section{Results \\ Demographics}

A total of 624 ETV patients and 93 re-ETV patients were included for analysis. See Table 1 for the baseline demographics, Table 2 for the number of ETV and reETV cases performed by each institution, and Fig. 2 for the flowchart for patient selection.

In 5 patients, a third ETV was performed; in 3 of these patients no subsequent treatment was needed and 2 patients received a shunt. Seven patients were excluded from the analysis; these patients had a patent ventriculostomy site and no other obstruction was found during neuroen- 
TABLE 3. Survival tables for ETV and re-ETV

\begin{tabular}{ccc}
\hline Yrs After & \multicolumn{2}{c}{ \% Cumulative Survival $(95 \% \mathrm{Cl})$} \\
\cline { 2 - 3 } Treatment & ETV & Re-ETV \\
\hline 0.5 & $67.6(63.9-71.3)$ & $67.6(57.9-77.3)$ \\
\hline 1 & $62.7(58.8-66.6)$ & $65.1(55.2-75.0)$ \\
\hline 3 & $55.2(51.0-59.4)$ & $50.3(39.1-61.5)$ \\
\hline 5 & $51.5(47.0-56.0)$ & $44.3(32.5-56.1)$ \\
\hline 7 & $45.9(40.9-51.0)$ & $44.3(32.5-56.0)$ \\
\hline
\end{tabular}

doscopic surgery. Three patients died of hydrocephalusrelated causes: 2 patients had an earlier failure of ETV, after which they received a shunt that subsequently failed but they were referred too late and died. The remaining patient, who had a nonpremature birth with neonatal cerebral hemorrhage (resulting in hydrocephalus that was treated with a shunt), was a severely mentally challenged, spastic child with infantile encephalopathy, who, at the age of 17 years, was admitted to the intensive care unit with suspected aspiration of blood and obstructed airways, gastroscopy, and multiple other diagnoses. This patient developed bradycardia, after which MRI of the cerebrum showed a trapped fourth ventricle and compression of the brainstem. ETV with aqueduct stenting proved insufficient and eventually the patient died.

Several techniques were used for the ETV procedures. The most commonly used was a dumbbell-shaped balloon for dilating the stoma; other methods used included thulium laser ablation of the third ventricle floor and a "black" fiber tip/diode laser combination for controlled tissue ablation. ${ }^{62}$

The median follow-up duration for the ETV procedures was 31.4 months (IQR 1.6-49.7 months), and the median
TABLE 4. Hazard ratios from the multivariable Cox proportional hazards model

\begin{tabular}{lccc}
\hline \multicolumn{1}{c}{ Variable } & HR & $95 \% \mathrm{Cl}$ & p Value \\
\hline Re-ETV relative to ETV & 1.23 & $0.90-1.69$ & 0.20 \\
\hline ETVSS & & & \\
\hline High ETVSS $(\geq 80)$ & Ref & Ref & Ref \\
\hline Low ETVSS $(\leq 40)$ & 4.24 & $3.09-5.81$ & $<0.001$ \\
\hline Moderate ETVSS $(50-70)$ & 2.08 & $1.61-2.70$ & $<0.001$ \\
\hline
\end{tabular}

Ref $=$ reference.

follow-up duration for the re-ETV procedures was 14.8 months (IQR 1.2-49.9 months).

The median age at the initial ETV was 4.8 years (IQR $0.5-11.6$ years), and the mean ETVSS for the initial ETV was 67 (SD 17). The median age at re-ETV was 6.1 years (IQR 1.0-12.4 years), and the mean ETVSS for re-ETV was 71 (SD 16). There were 5 patients older than 18 years at re-ETV $(19,19,21,22$, and 26 years).

The median time between ETV and re-ETV was 10.6 months (IQR 3.8-29.4 months). The median time between ETV and failure was 1.4 months (IQR 0.6-9.2 months), and the last failure occurred after 11.8 years. The median time between re-ETV and failure was 1.7 months (IQR $0.5-14.7$ months), and the last failure occurred after 8.0 years.

See Table 3 for the success rates for ETV and re-ETV over time and Fig. 3 for the Kaplan-Meier survival curves. The hazard ratios are shown in Table 4.

\section{Validity Evidence for Predictive Modeling}

For the initial ETV procedure, the mean ETVSS was significantly higher for successful cases than for failed

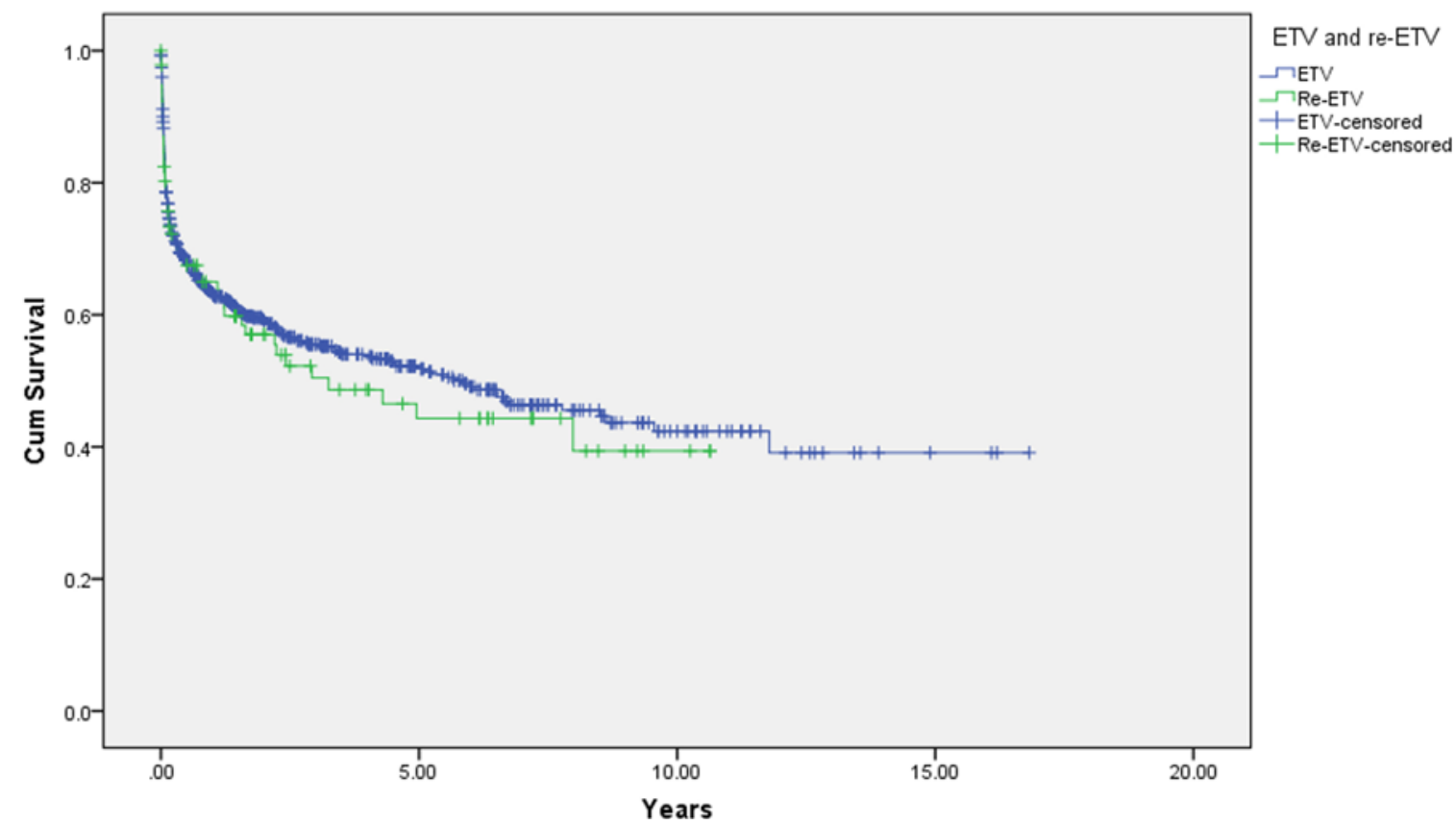

FIG. 3. Kaplan-Meier survival curves for ETV and re-ETV. $p=0.58$, log-rank test. Cum $=$ cumulative. Figure is available in color online only. 
TABLE 5. Characteristics of re-ETV success and failure at 6 months*

\begin{tabular}{|c|c|c|c|}
\hline \multirow[b]{2}{*}{ Characteristic } & \multicolumn{3}{|c|}{ No. of Patients (\%) } \\
\hline & $\begin{array}{l}\text { Success } \\
(n=57)\end{array}$ & $\begin{array}{l}\text { Failure } \\
(n=29)\end{array}$ & $\begin{array}{c}\text { Total } \\
(n=86)\end{array}$ \\
\hline \multicolumn{4}{|l|}{ Origin of hydrocephalus } \\
\hline Aqueductal stenosis & $11(19.3)$ & $8(27.6)$ & $19(22.1)$ \\
\hline Postinfectious & $1(1.8)$ & $1(3.4)$ & $2(2.3)$ \\
\hline Myelomeningocele & $3(5.3)$ & $2(6.9)$ & $5(5.8)$ \\
\hline Intraventricular hemorrhage & $4(7.0)$ & $2(6.9)$ & $6(7.0)$ \\
\hline Tectal tumor & $13(22.8)$ & $1(3.4)$ & $14(16.3)$ \\
\hline Other brain tumor (non-midbrain) & $8(14.0)$ & $5(17.2)$ & $13(15.1)$ \\
\hline Other† & $17(29.8)$ & $10(34.5)$ & $27(31.4)$ \\
\hline \multicolumn{4}{|l|}{ Age at re-ETV } \\
\hline$<1 \mathrm{mo}$ & 0 & 0 & 0 \\
\hline $1-6$ mos & $5(8.8)$ & $8(27.6)$ & $13(15.1)$ \\
\hline 6 mos to $<1 \mathrm{yr}$ & $6(10.5)$ & $5(17.2)$ & $11(12.8)$ \\
\hline $1-10 \mathrm{yrs}$ & $22(38.6)$ & $11(37.9)$ & $33(38.4)$ \\
\hline$\geq 10 \mathrm{yrs}$ & $24(42.1)$ & $5(17.2)$ & $29(33.7)$ \\
\hline \multicolumn{4}{|l|}{ Sex } \\
\hline Male & $31(54.4)$ & $15(51.7)$ & $46(53.5)$ \\
\hline Female & $26(45.6)$ & $14(48.3)$ & $40(46.5)$ \\
\hline \multicolumn{4}{|l|}{ Shunt prior to re-ETV } \\
\hline Yes & $11(19.3)$ & $14(48.3)$ & $25(29.1)$ \\
\hline No & $46(80.7)$ & $15(51.7)$ & $61(70.9)$ \\
\hline \multicolumn{4}{|l|}{ Closed ventriculostomy site $\neq$} \\
\hline Yes & $30(56.6)$ & $8(27.6)$ & $38(46.3)$ \\
\hline No & $23(43.4)$ & $21(72.4)$ & $44(53.7)$ \\
\hline \multicolumn{4}{|c|}{ Additional subarachnoid membranes§ } \\
\hline Yes & $17(32.1)$ & $19(65.5)$ & $36(43.9)$ \\
\hline No & $36(67.9)$ & $10(34.5)$ & $46(56.1)$ \\
\hline \multicolumn{4}{|l|}{ LP or ELD placementף } \\
\hline Yes & $13(24.5)$ & $7(24.1)$ & $20(24.4)$ \\
\hline No & $40(75.5)$ & $22(75.9)$ & $62(75.6)$ \\
\hline \multicolumn{4}{|l|}{ EVD placement ${ }^{\star *}$} \\
\hline Yes & $2(3.7)$ & $9(31.0)$ & 11 (13.3) \\
\hline No & $52(96.3)$ & $20(69.0)$ & 72 (86.7) \\
\hline
\end{tabular}

* Seven patients were lost to follow-up or died within 6 months and were excluded from analysis.

† See Table 6 for a list of conditions.

$\ddagger$ Four missing values.

$\S$ Four missing values.

If Four missing values.

** Three missing values.

cases at 6 months: 72 (SD 15) versus 57 (SD 18) (p < $0.001)$. The c-statistic for the 6-month follow-up was 0.74 (95\% CI 0.70-0.79). The ETVSS of the initial ETV was significantly related to the chances of ETV success $(\tau=$ 0.36 ; $95 \%$ bias corrected and accelerated CI $0.29-0.42 ; \mathrm{p}$ $<0.001)$.

For the re-ETV procedure, the mean ETVSS was significantly higher for successful cases than for failed cases at 6 months: 76 (SD 13) versus 63 (SD 16) (p < 0.001). The c-statistic for the 6-month follow-up was 0.74 (95\%
TABLE 6. Conditions included in the "other" category for origin of hydrocephalus $(n=27)$

\begin{tabular}{lc}
\hline \multicolumn{1}{c}{ Etiology } & No. of Patients (\%) \\
\hline Walker-Waarburg syndrome & $1(3.7)$ \\
\hline Dandy-Walker syndrome & $6(22.2)$ \\
\hline Arachnoid cyst & $12(44.4)$ \\
\hline Unknown & $1(3.7)$ \\
\hline 3rd ventricle cyst & $3(11.1)$ \\
\hline Neurofibromatosis Type 1 & $1(3.7)$ \\
\hline 4th ventricle outlet syndrome & $1(3.7)$ \\
\hline Vein of Galen malformation & $2(7.4)$ \\
\hline
\end{tabular}

CI 0.64-0.85). The ETVSS of re-ETV was significantly related to changes of re-ETV success $(\tau=0.37 ; 95 \%$ bias corrected and accelerated CI 0.21-0.52; $<<0.001)$.

\section{Successfully Versus Unsuccessfully Treated Re-ETV Patients}

For the 93 re-ETV patients, an in-depth analysis was conducted (see Tables 5 and 6 for the demographics of the failed and successful cases). Seven patients had less than 6 months of follow-up or died before 6 months (not hydrocephalus related) and were excluded from the analysis in this section. Only 1 patient received additional choroid plexus cauterization at re-ETV; 2 months after the procedure, the patient received a CSF shunt.

In the successfully treated patients, the median age at re-ETV was significantly higher than in unsuccessfully treated patients at 6 months of follow-up: 8.2 years (IQR $1.8-13.5$ years) versus 1.6 years (IQR $0.4-8.6$ years) $(\mathrm{p}=$ 0.002 ).

The median time between ETV and re-ETV did not differ significantly between successful and unsuccessful cases: 12.1 months (IQR 5.6-29.4 months) versus 7.6 months (IQR 1.6-29.7 months) $(\mathrm{p}=0.17)$.

\section{Shunting Prior to Re-ETV}

The failure rate for patients with a shunt prior to reETV was 56\% (14 of 25 patients). Of the 25 patients with a shunt prior to re-ETV, only 10 patients received the shunt between the initial ETV and re-ETV surgery. Of these 10 patients, the re-ETV of 8 patients $(80 \%)$ failed within 6 months. Of these 8 patients, 6 patients had subarachnoid membranes and 1 patient had massive prepontine adhesions. The remaining 15 patients already had received a shunt prior to the initial ETV.

\section{Effect of Intraoperative Findings}

In 4 patients, intraoperative findings were missing from documentation; thus, data from 82 patients were available for analysis. If the ventriculostomy site was closed and reopened, the patient had a significantly higher chance of success than when no closed ventriculostomy site was found during surgery. Based on the OR, the odds of success were 3.4 times higher (95\% CI 1.3-9.1; $\mathrm{p}=0.01$ ).

When additional subarachnoid membranes were ob- 
served during re-ETV surgery, the patient had a significantly greater chance to need subsequent hydrocephalus treatment within 6 months. Based on the OR, the odds of failure were 4.0 times higher (95\% CI 1.5-10.5; $\mathrm{p}=0.004)$.

\section{Effect of Postoperative Management}

Two patients underwent EVD placement after intraoperative bleeding. One patient had multiple thick prepontine arachnoid membranes, and the CSF of the other patient was a bit cloudy (suspected infection). In the remaining cases, no specific reasons for leaving an EVD was mentioned, and therefore we considered the EVD as being for escape reasons (i.e., to divert CSF in an emergency). It is not clear whether these escape EVDs were planned or whether it was the intraoperative call of the surgeon. When an EVD was placed, the patient had a significantly higher chance of needing subsequent hydrocephalus treatment within 6 months. Based on the OR, the odds of failure were 9.7 times higher (95\% CI 3.4-27.8; $p=0.001)$.

Performing an LP or ELD after re-ETV did not influence the chance of success at 6 months $(p=0.97)$.

\section{Discussion}

In the present study we observed a 7-year success rate for re-ETV of $44.3 \%$ (95\% CI 32.5\%-56.0\%). One large study from the CURE Children's Hospital of Uganda on 215 pediatric patients reported corresponding findings with a 7-year success for re-ETV of $51 \% .{ }^{45}$ The population of this group is not necessarily equal to the patient population found in the Western world (e.g., more cases of postinfectious hydrocephalus). The few published studies with 20-40 patients have reported reasonably good success rates between $63 \%$ and $81 \% .^{5,43,44,50,56}$ In other reports with fewer patients, the success rates range from $0 \%$ to $100 \%$. $^{21,23,26,28,31,33,34,48,53,60,64}$

Whereas some conclude that re-ETV should be considered in all patients who are referred with recurrent symptoms, others mention that re-ETV remains controversial. We think it is worthwhile to give ETV another chance in selected patients. Our primary motivation for this suggestion is to avoid shunt dependency. Also, the chances of ETV success and re-ETV success are similar; the adjusted estimate of the hazard ratio for re-ETV failure relative to ETV failure is 1.23 (95\% CI 0.90-1.69).

\section{Effect of Time}

There is great heterogeneity among the patient populations in the aforementioned studies (not all are pediatric populations), and it is rare to find the method used to calculate the follow-up duration.

In the literature on re-ETV, there seems to be a trend toward lower success rates in younger patients. ${ }^{37}$ This does not come as a surprise, as similar findings have been reported for initial ETV procedures. ${ }^{3,34}$ In the ETVSS proposed by Kulkarni et al., $50 \%$ of the total score is estimated by age alone. ${ }^{37}$

We also found that the patients in whom re-ETV was successful at 6 months after treatment were significantly older than unsuccessfully treated patients, but they did not have a longer time between their initial and re-ETV than unsuccessfully treated cases. However, on face value the suggestion is that longer duration might be associated with success. The lack of a statistically significant finding might be a statistical power issue of this cohort. Other authors have suggested that re-ETV seems worthwhile for patients with late failure of their ETV.$^{44,45}$ Furthermore, as has been extensively reported in the literature on initial ETV, we found that $64 \%$ of failures occurred within the first 6 months after re-ETV. ${ }^{21,26,35,42,53,55,63}$

Another reason for choosing ETV over shunt treatment is the apparent difference in concern among the parents of children with hydrocephalus. ${ }^{40}$ Although the comfort of parents could be a reason to prefer ETV over shunting, it can also make parents less cautious (i.e., provide a false sense of security), as there is no certainty of a cure for hydrocephalus, and late failure of ETV does occur with potential devastating results. ${ }^{14,19,27,60}$ In our study, the latest failures occurred 12 years after ETV and 8 years after re-ETV.

\section{Shunt Placement and Re-ETV}

A priori, one might argue that a shunt might allow a patient to age and thus increase the chance of re-ETV success (as age is a major factor in success). On the other hand, for initial ETV it has been shown that the chance of success diminishes if a shunt is placed prior to ETV surgery. ${ }^{37}$ In our cohort, 8 of 10 patients who received a shunt between ETV and re-ETV experienced failure of the re-ETV within 6 months. In 7 of 8 of these patients, subarachnoid membranes or even massive prepontine adhesions were found during re-ETV surgery. It is unclear whether there is a causal relationship between shunt implantation and the formation of subarachnoid membranes. This might be an interesting topic for a (prospective) follow-up study.

\section{Intraoperative Findings}

Some intraoperative and preoperative factors have been postulated to have predictive effects on ETV outcome (e.g., third ventricle floor thickness, prepontine scarring).,12,19,50,52,67,69 A thicker third ventricle floor has been negatively associated with ETV success, ${ }^{59}$ but unfortunately we could not retrospectively analyze this aspect. The presence of cisternal scarring has been negatively associated with success of the first ETV. ${ }^{67}$ We found that the presence of subarachnoid membranes and younger patient age had a negative effect on the chance of success. Similar findings were previously reported..$^{19,50}$

We found a positive effect of observed closure of the ventriculostomy site at re-ETV on the chance of short-term success. Other authors suggested that re-ETV should be considered if closure of the ventriculostomy site by gliosis and scarring is found during the second neuroendoscopic procedure. $6,8,11,46,54$

\section{Choroid Plexus Cauterization}

Combination with choroid plexus cauterization might give better results than ETV alone, as was shown in a cohort from the previously mentioned Uganda-based authors. ${ }^{65,68}$ In another study, it was shown that even when ETV could not be performed and the procedure had to be converted 
to a CSF shunt, the implanted shunt had a better chance of success if choroid plexus cauterization was performed. ${ }^{66} \mathrm{It}$ may be that ETV with choroid plexus cauterization has the largest effect in a subset of patients (e.g., patients with myelomeningocele). ${ }^{4,70}$ However, the possible favorable influence of choroid plexus cauterization in combination with ETV in developed countries is still being researched and debated and is beyond the scope of this study. $7,13,39,51,57,58,71$

\section{Postoperative Management}

Usage of an EVD had a negative effect on the chance of re-ETV success. It seems likely that a perioperative event made the surgeon proceed with caution but deterred the surgeon from converting to an internal shunt (e.g., bleeding during endoscopy or suspect infection). Postoperatively administering LP or ELD did not influence the chances of re-ETV success. The retrospective nature of our study is an obstacle in this aspect. It is not clear whether the postoperative use of LP or ELD are always well documented.

\section{Predictive Model}

We performed an additional analysis of ETVSS and found that the score adequately predicts the chance of success for patients undergoing re-ETV. The ETVSS of the successful cases was significantly higher than the ETVSS of the unsuccessful cases. The c-statistic ranges from 0.5 (no discrimination) to 1.0 (perfect discrimination). ${ }^{9}$ As a rough guideline, values between 0.7 and 0.9 indicate moderate accuracy. ${ }^{1,22}$ The c-statistic for ETVSS for re-ETV of 0.74 (95\% CI 0.64-0.85) was comparable to the findings of other validation studies on initial ETV procedures, including a study by our group in which we found an ETVSS of 0.82 (95\% CI 0.71-0.92). ${ }^{5,37,47}$ Kendall's tau coefficient showed a significant correlation between ETVSS and chances of both ETV and re-ETV success. The fact that ETVSS predicts the chances of re-ETV success as accurately as the chance of initial ETV success is another argument for the comparability of these 2 procedures. ETVSS takes few variables into account that have been shown over and over again to have an effect on the chance of short-term success of ETV, and now we show that these same factors can be used to predict the chance of re-ETV success.

\section{Limitations and Future}

The results of our study should be interpreted with caution due to limitations of its retrospective design. Because of this retrospective nature, we could not focus on some aspects that might be of importance. The thickness of the third ventricle floor has already been mentioned. Another is the motive for choosing re-ETV over shunt implantation (this is rarely clearly stated in documentation) with the possibility of selection bias. The decision-making process of the treating surgeons when selecting cases for re-ETV (or ETV) was beyond our control, but surgeons will have their own algorithm and will only select patients who they think will benefit from ETV or re-ETV. The relatively small sample of re-ETV cases is also a limitation. Finally, this study used a Dutch study population and the extent to which our results are generalizable to world-wide practice is not certain.
The description of flow void on postoperative MRI is missing in our analysis. Again, the retrospective design is a limiting factor. It has been postulated that if a patient returns with symptoms of raised intracranial pressure and the disappearance of flow void artifacts (where it was shown before on MRI), re-ETV should be considered. ${ }^{8}$ In other cases, shunt implantation may be a better option. Within our group, opinions differed on follow-up MRI regarding the duration of routine patient surveillance and under whose supervision this surveillance should take place (neurologist, pediatrician, neurosurgeon, or general practitioner).

One of the more notable findings was the diverse pattern of practice when the initial ETV failed. We intend to reveal these patterns with a survey study in which we target pediatric neurosurgeons who face the difficulties of treating pediatric hydrocephalus on a regular basis.

\section{Conclusions}

Re-ETV seems to be as safe and effective as initial ETV. ${ }^{24,56}$ The factors related to the success of re-ETV are similar to those related to the success of initial ETV (e.g., patient age and etiology of hydrocephalus). Other elements that negatively influence the chance of success are the presence of prepontine arachnoid membranes, use of EVD after the endoscopic procedure, and a short time interval between initial and re-ETV. The avoidance of lifelong shunt dependency in successful re-ETV cases is important, and therefore we recommend performing reETV in selected patients. ETVSS adequately predicts the chance of success and can be used for patient selection for re-ETV.

\section{Appendix}

\section{Dutch Pediatric Neurosurgery Study Group}

Amsterdam

Peter Vandertop, MD, PhD, Emma Children's Hospital, Neurosurgical Center Amsterdam

Dennis Buis, MD, PhD, Emma Children's Hospital, Neurosurgical Center Amsterdam

Hedy Folkersma, MD, PhD, Emma Children's Hospital, Neurosurgical Center Amsterdam

Pim van Ouwerkerk, MD, PhD, VU University Medical Center Groningen

Eelco Hoving, MD, PhD, Beatrix Children's Hospital, UniverLeiden sity Medical Center Groningen

Radboud Koot, MD, PhD, Willem-Alexander Children's Hospital, Leiden University Medical Center

Maastricht

Erwin Cornips, MD, Maastricht University Medical Center

Nijmegen

Erik J. van Lindert, MD, PhD, Amalia Children's Hospital, Radboud University Nijmegen Medical Center

Hans Delye, MD, PhD, Amalia Children's Hospital, Radboud University Nijmegen Medical Center

\section{Rotterdam}

Marie Lise van Veelen, MD, Sophia Children's Hospital, Erasmus University Medical Center

Ruben Dammers, MD, PhD, Sophia Children's Hospital, Erasmus University Medical Center

Rob de Jong, MD, Sophia Children's Hospital, Erasmus University Medical Center 
Utrecht

Sen Han, MD, PhD, Wilhelmina Children's Hospital, University Medical Center Utrecht

Peter Woerdeman, MD, PhD, Wilhelmina Children's Hospital, University Medical Center Utrecht

\section{Acknowledgments}

Sebastian Arts helped with the gathering of data at Nijmegen, and Mariam Slot helped at the VU University Medical Center.

\section{References}

1. Akobeng AK: Understanding diagnostic tests 3: Receiver operating characteristic curves. Acta Paediatr 96:644-647, 2007

2. Algin O: Prediction of endoscopic third ventriculostomy (ETV) success with 3D-SPACE technique. Neurosurg Rev 38:395-397, 2015

3. Baldauf J, Oertel J, Gaab MR, Schroeder HWS: Endoscopic third ventriculostomy in children younger than 2 years of age. Childs Nerv Syst 23:623-626, 2007

4. Beuriat PA, Szathmari A, Grassiot B, Plaisant F, Rousselle C, Mottolese C: Role of endoscopic third ventriculostomy in the management of myelomeningocele-related hydrocephalus: a retrospective study in a single French institution. World Neurosurg 87:484-493, 2016

5. Breimer GE, Sival DA, Brusse-Keizer MGJ, Hoving EW: An external validation of the ETVSS for both short-term and long-term predictive adequacy in 104 pediatric patients. Childs Nerv Syst 29:1305-1311, 2013

6. Buxton N, Ho KJ, Macarthur D, Vloeberghs M, Punt J, Robertson I: Neuroendoscopic third ventriculostomy for hydrocephalus in adults: report of a single unit's experience with 63 cases. Surg Neurol 55:74-78, 2001

7. Chamiraju P, Bhatia S, Sandberg DI, Ragheb J: Endoscopic third ventriculostomy and choroid plexus cauterization in posthemorrhagic hydrocephalus of prematurity. J Neurosurg Pediatr 13:433-439, 2014

8. Cinalli G, Sainte-Rose C, Chumas P, Zerah M, Brunelle F, Lot $\mathrm{G}$, et al: Failure of third ventriculostomy in the treatment of aqueductal stenosis in children. J Neurosurg 90:448-454, 1999

9. Cook NR: Use and misuse of the receiver operating characteristic curve in risk prediction. Circulation 115:928-935, 2007

10. Di Rocco C, Massimi L, Tamburrini G: Shunts vs endoscopic third ventriculostomy in infants: are there different types and/or rates of complications? A review. Childs Nerv Syst 22:1573-1589, 2006

11. Di Rocco F, Jucá CE, Zerah M, Sainte-Rose C: Endoscopic third ventriculostomy and posterior fossa tumors. World Neurosurg 79 (2 Suppl):S18.e15-S18.e19, 2013

12. Dlouhy BJ, Capuano AW, Madhavan K, Torner JC, Greenlee JDW: Preoperative third ventricular bowing as a predictor of endoscopic third ventriculostomy success. J Neurosurg Pediatr 9:182-190, 2012

13. Drake J: Editorial. Endoscopic third ventriculostomy. J Neurosurg Pediatr 10:461-462, 2012

14. Drake J, Chumas P, Kestle J, Pierre-Kahn A, Vinchon M, Brown J, et al: Late rapid deterioration after endoscopic third ventriculostomy: additional cases and review of the literature. J Neurosurg 105 (2 Suppl):118-126, 2006

15. Drake JM: Endoscopic third ventriculostomy in pediatric patients: the Canadian experience. Neurosurgery 60:881-886, 2007

16. Drake JM, Kulkarni AV, Kestle J: Endoscopic third ventriculostomy versus ventriculoperitoneal shunt in pediatric patients: a decision analysis. Childs Nerv Syst 25:467-472, 2009
17. Durnford AJA, Kirkham FJ, Mathad N, Sparrow OCEO: Endoscopic third ventriculostomy in the treatment of childhood hydrocephalus: validation of a success score that predicts long-term outcome. J Neurosurg Pediatr 8:489493, 2011

18. El-Ghandour NMF: Endoscopic third ventriculostomy versus ventriculoperitoneal shunt in the treatment of obstructive hydrocephalus due to posterior fossa tumors in children. Childs Nerv Syst 27:117-126, 2011

19. Faggin R, Calderone M, Denaro L, Meneghini L, d'Avella D: Long-term operative failure of endoscopic third ventriculostomy in pediatric patients: the role of cine phase-contrast MR imaging. Neurosurg Focus 30(4):E1, 2011

20. Fani L, de Jong THR, Dammers R, van Veelen MLC: Endoscopic third ventriculocisternostomy in hydrocephalic children under 2 years of age: appropriate or not? A single-center retrospective cohort study. Childs Nerv Syst 29:419-423, 2013

21. Feng H, Huang G, Liao X, Fu K, Tan H, Pu H, et al: Endoscopic third ventriculostomy in the management of obstructive hydrocephalus: an outcome analysis. J Neurosurg 100:626-633, 2004

22. Fischer JE, Bachmann LM, Jaeschke R: A readers' guide to the interpretation of diagnostic test properties: clinical example of sepsis. Intensive Care Med 29:1043-1051, 2003

23. Fukuhara T, Luciano MG, Kowalski RJ: Clinical features of third ventriculostomy failures classified by fenestration patency. Surg Neurol 58:102-110, 2002

24. Gallo P, Sala F: The role of repeat endoscopic third ventriculostomy after failure of the initial procedure. Neurol India 59:844-845, 2011

25. García LG, López BR, Botella GI, Páez MD, da Rosa SP, Rius F, et al: Endoscopic third ventriculostomy success score (ETVSS) predicting success in a series of 50 pediatric patients. Are the outcomes of our patients predictable? Childs Nerv Syst 28:1157-1162, 2012

26. Grand W, Leonardo J, Chamczuk AJ, Korus AJ: Endoscopic third ventriculostomy in 250 adults with hydrocephalus: patient selection, outcomes, and complications. Neurosurgery 78:109-119, 2016

27. Hader WJ, Drake J, Cochrane D, Sparrow O, Johnson ES, Kestle J: Death after late failure of third ventriculostomy in children. Report of three cases. J Neurosurg 97:211-215, 2002

28. Hellwig D, Giordano M, Kappus C: Redo third ventriculostomy. World Neurosurg 79 (2 Suppl):S22.e13-S22.e20, 2013

29. Hellwig D, Grotenhuis JA, Tirakotai W, Riegel T, Schulte DM, Bauer BL, et al: Endoscopic third ventriculostomy for obstructive hydrocephalus. Neurosurg Rev 28:1-34, 2005

30. Jernigan SC, Berry JG, Graham DA, Goumnerova L: The comparative effectiveness of ventricular shunt placement versus endoscopic third ventriculostomy for initial treatment of hydrocephalus in infants. J Neurosurg Pediatr 13:295-300, 2014

31. Kadrian D, van Gelder J, Florida D, Jones R, Vonau M, Teo $\mathrm{C}$, et al: Long-term reliability of endoscopic third ventriculostomy. Neurosurgery 56:1271-1278, 2005

32. Kahle KT, Kulkarni AV, Limbrick DD Jr, Warf BC: Hydrocephalus in children. Lancet 387:788-799, 2016

33. Koch D, Grunert P, Filippi R, Hopf N: Re-ventriculostomy for treatment of obstructive hydrocephalus in cases of stoma dysfunction. Minim Invasive Neurosurg 45:158-163, 2002

34. Koch-Wiewrodt D, Wagner W: Success and failure of endoscopic third ventriculostomy in young infants: are there different age distributions? Childs Nerv Syst 22:1537-1541, 2006

35. Kulkarni AV, Drake JM, Kestle JRW, Mallucci CL, Sgouros S, Constantini S: Predicting who will benefit from endoscopic third ventriculostomy compared with shunt insertion 
in childhood hydrocephalus using the ETV Success Score. J Neurosurg Pediatr 6:310-315, 2010

36. Kulkarni AV, Drake JM, Kestle JRW, Mallucci CL, Sgouros S, Constantini S: Endoscopic third ventriculostomy vs cerebrospinal fluid shunt in the treatment of hydrocephalus in children: a propensity score-adjusted analysis. Neurosurgery 67:588-593, 2010

37. Kulkarni AV, Drake JM, Mallucci CL, Sgouros S, Roth J, Constantini S: Endoscopic third ventriculostomy in the treatment of childhood hydrocephalus. J Pediatr 155:254-259, 259.e1, 2009

38. Kulkarni AV, Hui S, Shams I, Donnelly R: Quality of life in obstructive hydrocephalus: endoscopic third ventriculostomy compared to cerebrospinal fluid shunt. Childs Nerv Syst 26:75-79, 2010

39. Kulkarni AV, Riva-Cambrin J, Browd SR, Drake JM, Holubkov R, Kestle JRW, et al: Endoscopic third ventriculostomy and choroid plexus cauterization in infants with hydrocephalus: a retrospective Hydrocephalus Clinical Research Network study. J Neurosurg Pediatr 14:224-229, 2014

40. Kulkarni AV, Shams I, Cochrane DD, McNeely PD: Does treatment with endoscopic third ventriculostomy result in less concern among parents of children with hydrocephalus? Childs Nerv Syst 26:1529-1534, 2010

41. Kulkarni AV, Shams I, Cochrane DD, McNeely PD: Quality of life after endoscopic third ventriculostomy and cerebrospinal fluid shunting: an adjusted multivariable analysis in a large cohort. J Neurosurg Pediatr 6:11-16, 2010

42. Labidi M, Lavoie P, Lapointe G, Obaid S, Weil AG, Bojanowski MW, et al: Predicting success of endoscopic third ventriculostomy: validation of the ETV Success Score in a mixed population of adult and pediatric patients. J Neurosurg 123:1447-1455, 2015

43. Lam S, Harris D, Rocque BG, Ham SA: Pediatric endoscopic third ventriculostomy: a population-based study. J Neurosurg Pediatr 14:455-464, 2014

44. Mahapatra A, Mehr S, Singh D, Tandon M, Ganjoo P, Singh $\mathrm{H}$ : Ostomy closure and the role of repeat endoscopic third ventriculostomy (re-ETV) in failed ETV procedures. Neurol India 59:867-873, 2011

45. Marano PJ, Stone SSD, Mugamba J, Ssenyonga P, Warf EB, Warf BC: Reopening of an obstructed third ventriculostomy: long-term success and factors affecting outcome in 215 infants. J Neurosurg Pediatr 15:399-405, 2015

46. Mohanty A, Vasudev MK, Sampath S, Radhesh S, Sastry Kolluri VR: Failed endoscopic third ventriculostomy in children: management options. Pediatr Neurosurg 37:304-309, 2002

47. Naftel RP, Reed GT, Kulkarni AV, Wellons JC: Evaluating the Children's Hospital of Alabama endoscopic third ventriculostomy experience using the Endoscopic Third Ventriculostomy Success Score: an external validation study. J Neurosurg Pediatr 8:494-501, 2011

48. Navarro R, Gil-Parra R, Reitman AJ, Olavarria G, Grant JA, Tomita T: Endoscopic third ventriculostomy in children: early and late complications and their avoidance. Childs Nerv Syst 22:506-513, 2006

49. Nishiyama K, Yoshimura J, Fujii Y: Limitations of Neuroendoscopic Treatment for Pediatric Hydrocephalus and Considerations from Future Perspectives. Neurol Med Chir (Tokyo) 55:611-616, 2015

50. Peretta P, Cinalli G, Spennato P, Ragazzi P, Ruggiero C, Aliberti F, et al: Long-term results of a second endoscopic third ventriculostomy in children: retrospective analysis of 40 cases. Neurosurgery 65:539-547, 2009

51. Riva-Cambrin J, Spader H, Kulkarni A, Warf B, Mugamba J, Ssenyonga P: Attitudes regarding endoscopic third ventriculostomy and choroid plexus coagulation $(\mathrm{ETV}+\mathrm{CPC})$ and the effect of training at CURE Children's Hospital, Uganda among North American pediatric neurosurgeons. Fluids Barriers CNS 12 (Suppl 1):O10, 2015

52. Romero L, Ros B, Ibáñez G, Ríus F, González L, Arráez M: Endoscopic third ventriculostomy: can we predict success during surgery? Neurosurg Rev 37:89-97, 2014

53. Sacko O, Boetto S, Lauwers-Cances V, Dupuy M, Roux FE: Endoscopic third ventriculostomy: outcome analysis in 368 procedures. J Neurosurg Pediatr 5:68-74, 2010

54. Sgouros S (ed): Neuroendoscopy. Current Status and Future Trends. Berlin: Springer, 2014

55. Siomin V, Cinalli G, Grotenhuis A, Golash A, Oi S, Kothbauer K, et al: Endoscopic third ventriculostomy in patients with cerebrospinal fluid infection and/or hemorrhage. J Neurosurg 97:519-524, 2002

56. Siomin V, Weiner H, Wisoff J, Cinalli G, Pierre-Kahn A, Saint-Rose C, et al: Repeat endoscopic third ventriculostomy: is it worth trying? Childs Nerv Syst 17:551-555, 2001

57. Souweidane MS: Combined choroid plexus coagulation and endoscopic third ventriculostomy: is North America ready? J Neurosurg Pediatr 14:221-223, 2014

58. Stone SSD, Warf BC: Combined endoscopic third ventriculostomy and choroid plexus cauterization as primary treatment for infant hydrocephalus: a prospective North American series. J Neurosurg Pediatr 14:439-446, 2014

59. Sufianov AA, Sufianova GZ, Iakimov IA: Endoscopic third ventriculostomy in patients younger than 2 years: outcome analysis of 41 hydrocephalus cases. J Neurosurg Pediatr 5:392-401, 2010

60. Surash S, Chumas P, Bhargava D, Crimmins D, Straiton J, Tyagi A: A retrospective analysis of revision endoscopic third ventriculostomy. Childs Nerv Syst 26:1693-1698, 2010

61. Tuli S, Alshail E, Drake J: Third ventriculostomy versus cerebrospinal fluid shunt as a first procedure in pediatric hydrocephalus. Pediatr Neurosurg 30:11-15, 1999

62. van Beijnum J, Hanlo PW, Fischer K, Majidpour MM, Kortekaas MF, Verdaasdonk RM, et al: Laser-assisted endoscopic third ventriculostomy: long-term results in a series of 202 patients. Neurosurgery 62:437-444, 2008

63. Vulcu S, Eickele L, Cinalli G, Wagner W, Oertel J: Longterm results of endoscopic third ventriculostomy: an outcome analysis. J Neurosurg 123:1456-1462, 2015

64. Wagner W, Koch D: Mechanisms of failure after endoscopic third ventriculostomy in young infants. J Neurosurg 103 (1 Suppl):43-49, 2005

65. Warf BC: Comparison of endoscopic third ventriculostomy alone and combined with choroid plexus cauterization in infants younger than 1 year of age: a prospective study in 550 African children. J Neurosurg 103 (6 Suppl):475-481, 2005

66. Warf BC, Bhai S, Kulkarni AV, Mugamba J: Shunt survival after failed endoscopic treatment of hydrocephalus. J Neurosurg Pediatr 10:463-470, 2012

67. Warf BC, Kulkarni AV: Intraoperative assessment of cerebral aqueduct patency and cisternal scarring: impact on success of endoscopic third ventriculostomy in 403 African children. J Neurosurg Pediatr 5:204-209, 2010

68. Warf BC, Tracy S, Mugamba J: Long-term outcome for endoscopic third ventriculostomy alone or in combination with choroid plexus cauterization for congenital aqueductal stenosis in African infants. J Neurosurg Pediatr 10:108-111, 2012

69. Woodworth GF, See A, Bettegowda C, Batra S, Jallo GI, Rigamonti D: Predictors of surgery-free outcome in adult endoscopic third ventriculostomy. World Neurosurg 78:312-317, 2012

70. Zandian A, Haffner M, Johnson J, Rozzelle CJ, Tubbs RS, Loukas M: Endoscopic third ventriculostomy with/without choroid plexus cauterization for hydrocephalus due to hemorrhage, infection, Dandy-Walker malformation, and neural 
tube defect: a meta-analysis. Childs Nerv Syst 30:571-578, 2014

71. Zhu X, Di Rocco C: Choroid plexus coagulation for hydrocephalus not due to CSF overproduction: a review. Childs Nerv Syst 29:35-42, 2013

\section{Disclosures}

The authors report no conflict of interest concerning the materials or methods used in this study or the findings specified in this paper.

\section{Author Contributions}

Conception and design: Breimer, Hoving. Acquisition of data: Breimer, Dammers. Analysis and interpretation of data: Breimer,
Hoving. Drafting the article: Breimer. Critically revising the article: all authors. Reviewed submitted version of manuscript: all authors. Approved the final version of the manuscript on behalf of all authors: Breimer. Statistical analysis: Breimer, Brusse-Keizer. Study supervision: Hoving.

\section{Supplemental Information}

\section{Previous Presentations}

Portions of this work were published as an abstract in Childs Nerv Syst 2016;32(5):927 as a notification for the 25th Congress of the European Society for Pediatric Neurosurgery held in Paris, France, on May 8-11, 2016.

\section{Correspondence}

Gerben E. Breimer, Academic Medical Center (AMC), Meibergdreef 9, 1105 AZ Amsterdam, The Netherlands. email: g.e.breimer@amc.nl. 